\title{
SISTEM MONITORING KETERSEDIAAN BAHAN BAKU COR BETON MENGGUNAKAN METODE MARKET BASKET ANALYSIS
}

\author{
Rometdo Muzawi ${ }^{1)}$, Tashid ${ }^{2)}$, Mahadir Nasution ${ }^{3)}$ \\ ${ }^{1}$ Program Studi Manajemen Informatika, STMIK Amik Riau \\ email : rometdomuzawi@stmik-amik-riau.ac.id \\ ${ }^{2}$ Program Studi Manajemen Informatika, STMIK Amik Riau \\ email : tashid@stmik-amik-riau.ac.id \\ 3 Program Studi Teknik Informatika, STMIK Amik Riau \\ email : mahadirnasution@stmik-amik-riau.ac.id
}

\begin{abstract}
Cast concrete is very important in building physical buildings, both for the construction of houses, hotels, bridges, apartments and other physical buildings. The concrete cast material is the most chosen by the community in building buildings because it is easily formed according to the needs of construction and has a strong strength and is resistant to high temperatures. "Inventory is a component of material or finished product available in hand, waiting to be used or sold" (Groebner in Baroto, 2002: 52). Monitoring raw material inventory is a management function that is very important because inventory is a very large investment company, both in terms of value and future functions. So from that the company needs to implement planning regarding inventory control which estimates the accuracy between inputs into output and the accuracy of the quantity or volume of raw materials. In the real world there are many companies that have not noticed the importance of managing raw material inventories, this can be found in companies that experience excess raw materials in warehouses, as well as running out of raw materials. Monitoring inventory that is well implemented can trigger the success of a company in the production sector in a timely manner. In manufacturing companies often encountered a delay in the arrival of raw materials according to a predetermined schedule. This can create panic at the company's management if there is a stock out, where on the other hand the company must immediately fulfill the goods orders. Therefore, monitoring the availability of concrete cast materials is very important to support the smooth production and can avoid the vacuum of concrete cast material. If the availability of concrete cast raw materials does not monitor, it will cause difficulties in knowing whether or not there is still a concrete cast material to be produced. On this basis the author makes a monitoring system for the availability of concrete cast raw materials using the Market Basket Analysis method.
\end{abstract}

Keywords: monitoring system, raw materials, Market Basket Analysis 


\section{PENDAHULUAN}

Dalam membangun bangunan fisik, bahan baku cor beton adalah bahan bangunan yang paling banyak digunakan oleh masyarakat. Pada saat ini hamper semua masyarakat didunia menggunakan bahan baku cor beton sebagai bahan utama dalam membagun bangunan fisik. Untuk membangun unit bangunan perlu adanya bahan material yang cukup sesuai dengan kebutuhan bangunan, oleh karena itu monitoring ketersediaan bahan baku cor beton sangat perlu dan mutlak diperhatikan ketika membangun unit bangunan terlebih lagi bangunan untuk fasilitas umum yang berkapasistas besar.

Sistem Monitoring adalah tindakan pemantauan atas ketersediaan suatu objek yang dipantau agar selalu dapat diawasi keadaannya. Dalam bangunan, sistem monitoring ketersediaan bahan baku cor beton sangat di perlukan untuk memantau keadaan dan ketersediaan bahan bangunan agar terhindar dari stock out maupun delasy in delivery.

Salah satu metode yang dapat digunakan untuk memantau ketersediaan bahan baku cor beton adalah Market Basket Analysis. Market Basket Analysis adalah metode yang digunakan untuk menganalisa atas perilaku konsumen secara spesifik dari konsumen. Proses yang dilakukan adalah dengan menganalisis buying habits konsumen dengan menemukan asosiasi antar product yang berbedadan yang diletakkan konsumen dalam shopping basket. Hasil dari Market Basket Analisis adalah beruwujud aturan assosiasi (Assocition Rules). Association Rule adalah teknik data mining untuk menemukan aturan assosiatif antara suatu kombinasi item. Bentuk dari Association Rule adalah jika "kejadian sebelumnya" kemudian "konsekuensinya", (IF antecedent, THEN consequent). Bersamaan dengan perhitungan aturan support dan confidence.
Menurut Agus Suryantoro (2013:70) suatu sistem dapat didefinisikan sebagai suatu kesatuan yang terdiri dari dua atau lebih komponen atau sub sistem yang berinteraksi untuk mencapai suatu tujuan. Suatu sistem dapat terdiri dan sistem-sistem bagian (Subsystem).

\subsubsection{Pengertian Sistem}

Sistem adalah suatu jaringan kerja dari prosedur-prosedur yang saling berhubungan, berkumpul bersama-sama untuk melakukan sesuatu kegiatan untuk menyelesaikan suatu sasaran tertentu.

\subsubsection{Monitoring}

Adapun pengertian monitoring menurut para ahli:

1. Menurut Mudjahudin dan Putra (2010:75) Monitoring dapat didefinisikan sebagai suatu proses mengukur, mencatat, mengumpulkan, memproses dan mngkomunikasikan informasi untuk membantu pengambilan keputusan manajemen proyek.

2. Menurut Eric Clayton dan Francoise Petry (1983) Monitoring sebagai suatu proses mengukur, mencatat, mengumpulkan, memproses dan mengkomunikasikan informasi untuk membantu pengambilan keputusan manajemen program/proyek.

Monitoring adalah penilaian secara terus menerus terhadap fungsi kegiatan-kegiatan program di dalam hal jadwal penggunaan masukan data oleh kelompok sasaran berkaitan dengan harapan yang telah direncanakan yang bertujuan mendapatkan umpan balik bagi kebutuhan program proses pembelajaran yang sedang berjalan.

\subsubsection{Sistem Monitoring}

Sistem monitoringmerupakan suatu proses untuk mengumpulkan data yang real timedariberbagai sumber daya. Secara garis besar tahapan dalam sebuah sistem monitoring terbagi ke dalam tiga proses besar seperti yang terlihat pada gambar 2.1. yaitu:

1. Proses di dalam pengumpulan data monitoring. 
2. Proses di dalam analisis data monitoring.

3. Proses di dalam menampilkan data hasil montoring.

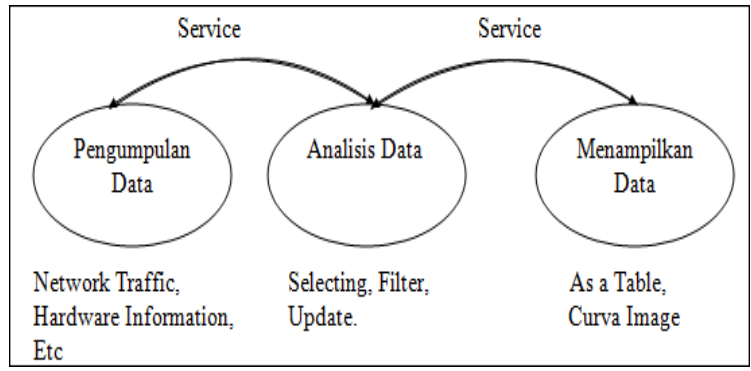

Gambar 2.1. Tahapan Sistem Monitoring

\subsubsection{Ketersediaan}

Setiap perusahaan, apakah itu perusahaan jasa ataupun perusahaan manufaktur selalu memerlukan ketersediaan. Tanpa adanya ketersediaan, para pengusaha akan dihadapkan pada resiko bahwa perusahaannya pada suatu waktu tidak dapat memenuhi keinginan para pelanggan yang dapat mengakibatkan para pelanggan pergi ke perusahaan lain. ketersediaan ini diadakan apabila keuntungan yang diharapkan dari ketersediaan tersebut terjamin kelancarannya. Adapun alasan diperlukannya ketersediaan oleh suatu perusahaan adalah:

1. Dibutuhkannya waktu untuk menyelesaikan operasi produksi dan untuk memindahkan produk dari suatu tingkat proses ke tingkat proses lainnya yang disebut ketersediaan dalam proses dan pemindahan.

2. Alasan Organisasi, untuk memungkinkan satu unit atau bagian dalam membuat jadwal operasinya secara bebas dan tidak tergantung dari yang lainnya.

\subsubsection{Bahan baku}

Adapun pengertian bahan baku menurut beberapa para ahli yaitu sebagai berikut:

1. Mulyadi (2005:275) bahan baku adalah Bahan baku merupakan bahan yang membentuk bagian menyeluruh.
2. Suyadi Prawirosentono (2001:61) Bahan baku adalah bahan utama dari suatu produk atau barang.

Dari definisi diatas dapat disimpulkan bahwa bahan baku merupakan bahan yang utama didalam melakukan proses produksi menjadi barang jadi.

\subsubsection{Beton}

Adapun pengertian beton menurut beberapa sumber adalah sebagai berikut:

1. Menurut Yufiter S.K, Ruslan R dan R. Cornelis (2012:75) Beton merupakan konstruksi yang mempunyai banyak kelebihan antara lain, kuat menahan gaya tekan, tahan terhadap perubahan cuaca, lebih tahan terhadap suhu tinggi, mudah dibentuk sesuai dengan kebutuhan dan mudah dikerjakan dengan cara mencampur semen, agregat, air, dan bahan tambahan lain bila diperlukan.

2. Menurut Soelarso, Baehaki, Nur Fatah Sidik (22:2016)Beton adalah salah satu teknologi konstruksi dalam disiplin ilmu bahan yang selalu berkembang hingga saat ini.

Beton adalah suatu material secara harfiah merupakan bentuk dasar kehidupan sosial modern yang terdiri dari campuranantara semen, air dan agregat.

\subsubsection{Market Basket Analysis \\ Market Basket Analysis merupakan metode analisis terhadap} kebiasaan customer berbelanja dengan cara menemukan asosiasi dan korelasi di antara berbagai macam item yang dimasukkan customer di dalam keranjang belanjaannya. Market Basket Analysis bertujuan untuk mengetahui item apa saja yang sering dibeli bersamaan oleh customer.

Market Basket Analysis merupakan penerapan dari metode Association Rule. Association Rule adalah teknik data mining untuk menemukan aturan assosiatif antara suatu kombinasi item dalam suatu data set dan menampilkannya dalam bentuk Association Rules.Tujuan Association Rulesuntuk menemukan relasi dankorelasi 
diantara himpunan item-item.

\subsubsection{Konsep Market Basket Analysis} Market Basket Analysis merupakan salah satu contoh penerapan Association Rule.Untuk menyampaikan ide mendasar dari Market Basket Analysis dimulai dengan melihat gambar keranjang belanjaan pada gambar II.2.yang berisi bermacam-macam barang yang dibeli oleh seseorang di sebuah toko bangunan. Keranjang ini berisi bermacam-macam barang seperti batu bata, semen, pasir halus, kerikil, besi dan sebagainya.Berikut ini adalah gambaran/ilustrasi dari konsep Market Basket Analisis:

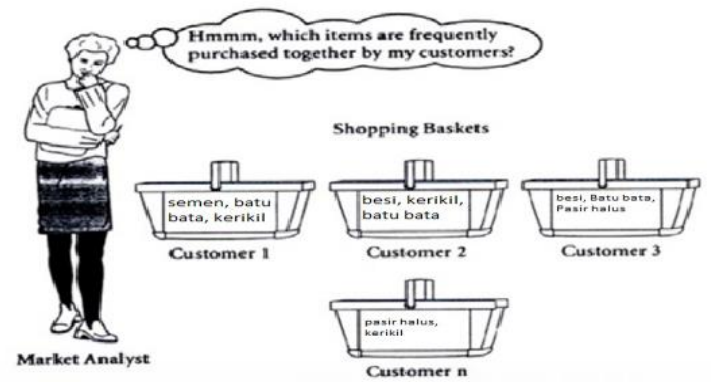

Gambar 2.2. Ilustrasi tentang konsep Market Basket Analysis

\section{METODE PENELITIAN}

Untuk mencapai keakuratan dan ketelitian data serta informasi dalam penelitian ini, maka pengumpulan data di lakukan dengan 3 cara :

1. Observasi, yaitu pengumpulan data dengan pengamatan langsung pada objek yang sedang diteliti untuk melihat sistem yang sedang berjalan dan kemudian disempurnakan.

2. Wawancara, yaitu melakukan Tanya jawab langsung dengan Manager CV. Baihaqi Perkasa.

3. Tinjauan Pustaka yaitu kegiatan yang meliputi mencari, membaca dan mendengarkan laporan-laporan penelitian dan bahan pustaka yang memuat teori-teori yang relevan dengan penelitian yang dilakukan.
Sistem monitoring ketersediaan barang yang berlangsung pada CV. Baihaqi Perkasa selama ini dapat dijelaskan proses persediaan yang dimulai dari penerimaan barang yang dilakukan oleh bagian pembelian, kemudian bagian gudang melakukan pengecekan barang yang dating sebelum disimpan dalam gudang. Barang yang tidak lolos dalam pengecekan dikembalikan kepada bagian pembelian untuk diretur kepada suplier. Bagian gudang menerima surat order dari bagian penjualan sesuai dengan kebutuhan customer, bagian gudang mengecek barang yang terdapat dalam gudang apakah mencukupi atau tidak untuk memenuhi kebutuhancustomer.

\section{PerancanganSistem}

\section{Entity Relationship Diagram (ERD)}

Pada dibawah ini terdapat Entity Relationship Diagram (ERD) sistem monitoring ketersediaan barang. Pada Entity Relationship Diagram (ERD) ini terdiri dari 6 entitas (bagian), yaitu bagian petugas, bagian tempo jual, suplier, jenis, jual dan barang. Masing-masing dari entity memberikan input.

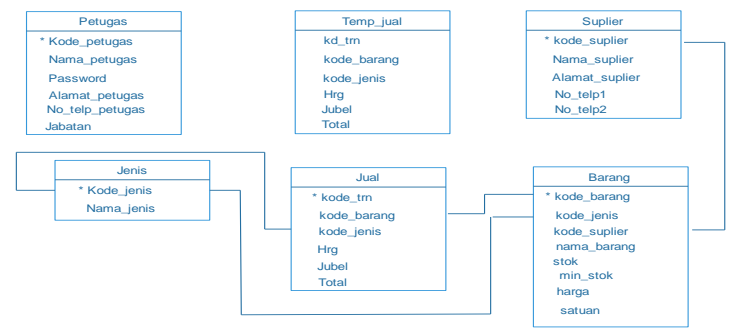

Entity Relationship Diagram Sistem Monitoring

\section{Pengujian Sistem Aplikasi}

Sistem aplikasi yang dibuat dapat digunakan untuk memonitoring ketersediaan bahan baku cor beton yang ada pada CV. Baihaqi Perkasa. Berikut adalah tampilan sistem aplikasi yang dibuat:
4. HASIL DAN PEMBAHASAN

Analisa Sistem Yang Sedang Berialan

\section{Menu Login}

Untuk menggunakan sistem 
aplikasi, pengguna harus login terlebih dahulu Jika login yang dilakukan user diterimaolehsistembarulah user dapat menggunakan sistem aplikasi tersebut.

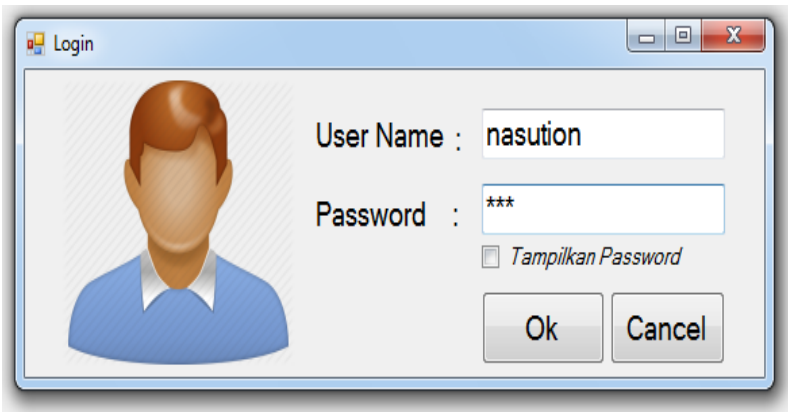

Layout Login User

\section{Menu Utama}

Jika User Berhasil Login, maka user akan masuk kehalaman utama dan dapat mengakses Data Master, Transaksi dan Laporan.

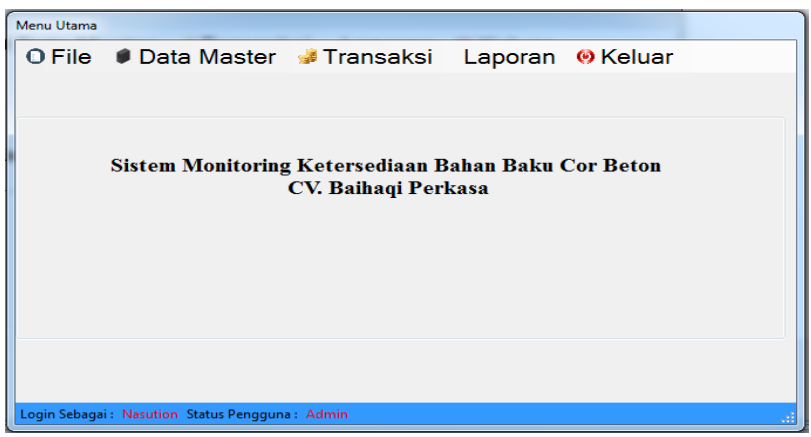

Layout Utama

\section{Menu Barang}

Menu barang berfungsi untuk menginputkan data-data barang yang telah diterima dari Suplier yang terdiri dari kode barang, nama barang, jenis barang, kode jenis, stok, minimal stok, harga satuan dan satuan

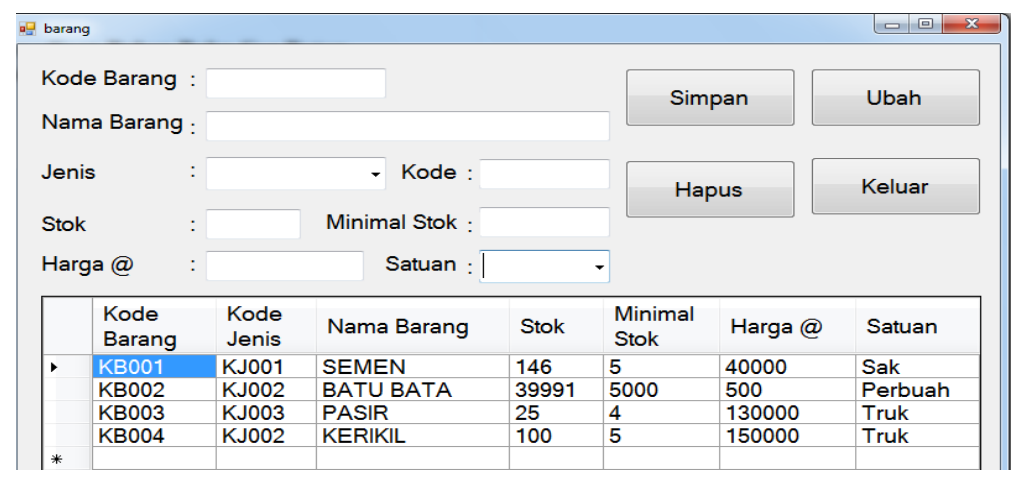

Layout Input Data Barang

\section{Form Suplier}

Pada form suplier pengguna dapat menginputkan data kode suplier, Nama suplier, alamat dan nomor telpon suplier

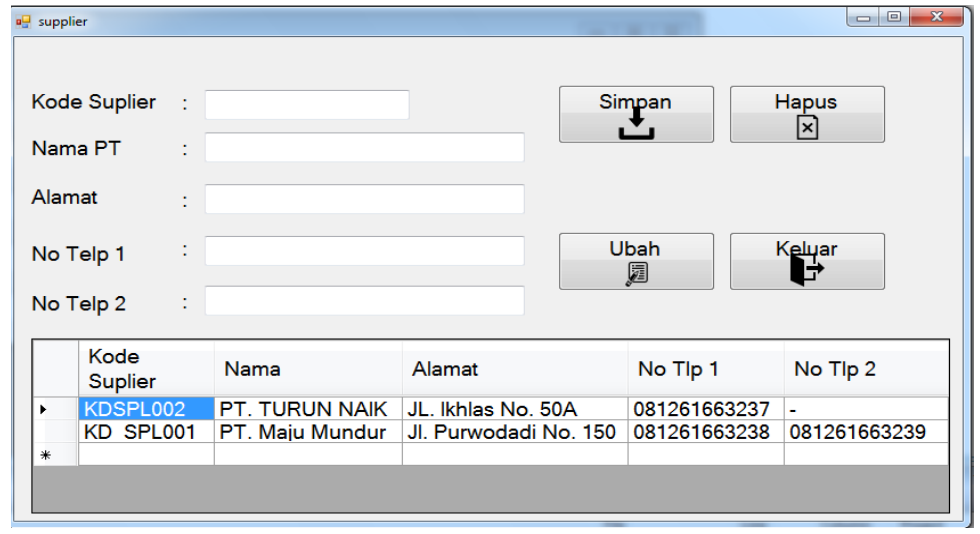

Layout Input Data Suplier

\section{IV.4.1. Form Jenis}

Form jenis barang digunakan untuk memisahkan jenis barang. Misalnya, nama Barang adalah pasir, jenisnya pasir halus dan kasar.

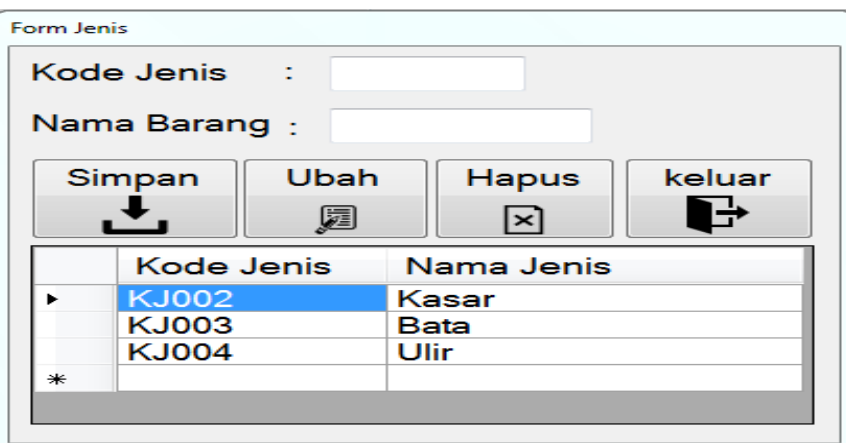

Layout Input Data Jenis Barang 


\section{Form Petugas}

Untuk mengakses sebuah sistem tidak sembarang orang dapat mengaksesnya, maka dari itu perlu adanya form petugas yang dapat atau yang diizinkan untuk mengkses sistem agar tidak sembarang orang yang dapat mengaksesnya.

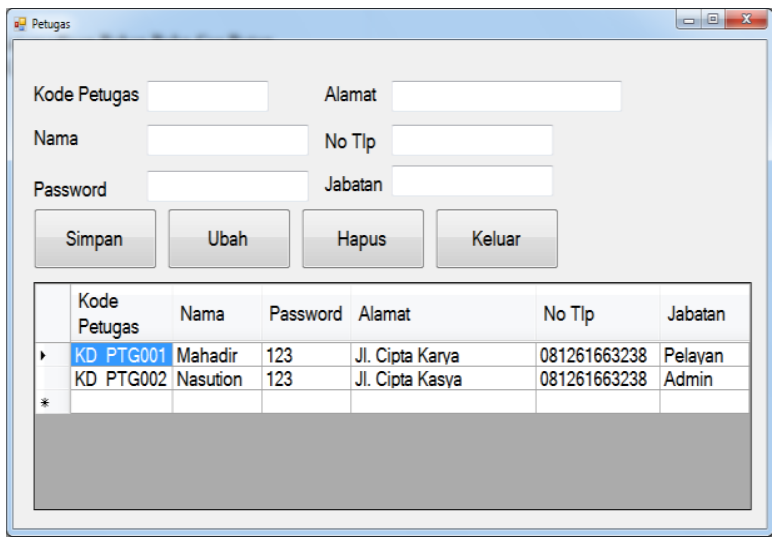

Layout Input Data Petugas

\section{Form Transaksi}

Form transaksi digunakan pada saat terjadinya transaksi pengeluaran barang dari gudang kepada konsumen. Dengan tujuan untuk memudahkan pengguna sistem dalam menghitung jumlah barang yang dikeluarkam dari transaksi tersebut serta memudahkan dalam menghitung total belanjaan konsumen yang datang berbelanja ke CV. Baihaqi Perkasa.

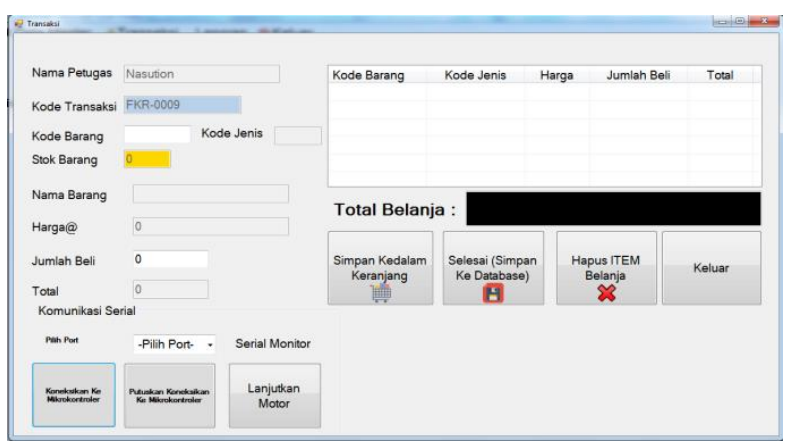

Layout Input Data Transaksi
Form persediaan digunaka untuk menampilkan informasi ketersediaan barang yang ada khusus untuk pengguna sistem. Adapun yang ditampilkan adalah kode barang, kode jenis, nama barang, stok, minimal stok, harga satuan dan satuan barang.

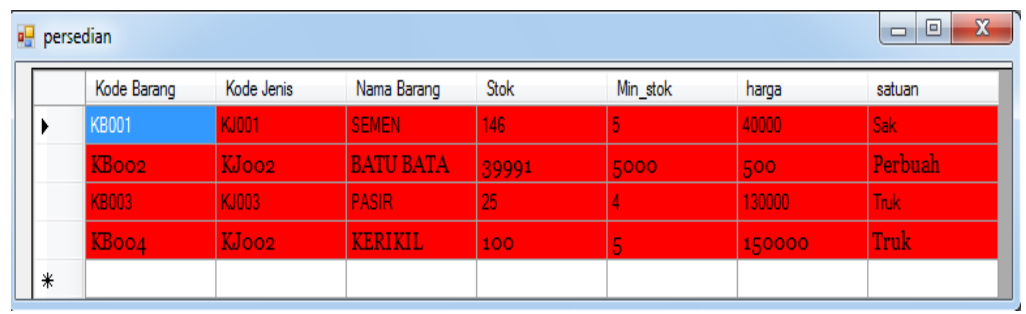

Layout Tabel Persediaan

\section{REFERENSI}

Suryantoro, Agus. 2009. Integrasi Aplikasi

Sistem Informasi Geografi. LP2IP,

Yogyakarta, Indonesia.

Mudjahidin, And Putra, N. P. 2010. Rancang

Bangun Sistem Informasi Monitoring

Perkembangan Proyek Berbasis Web Studi Kasus Di Dinas Bina Marga dan Pemantusan. Jurnal Teknik Industri. Vol.11, No.1:75- 83.

Soelarso. Baehaki. And Nur Fatah Sidik. 2016. Pengaruh penggunaan limbah beton sebagai pengganti agregat kasar pada beton normal terhadap kuat tekan dan modulus elastisitas. Jurnal Fondasi, Vol. 5, No.2: 23.

Yufiter S.K, Ruslan R dan R. Cornelis. 2012. Substitusi agregat halus beton menggunakan kapur alam dan menggunakan pasir laut pada campuran beton (Studi Analisis Bahan Kapur Alam dan Pasir Laut Dari Kabupaten Sumba Barat Daya Provinsi Nusa Tenggara

\section{Form Persediaan}


Dinata, A.K. 2013. Sistem Informasi Persediaan Barang Pada Distro Above Store Semarang. Universitas Dian Nusantara.

Sulaiman, A.W, Dkk. Perancangan Dan Implementasi Sistem Faktur Dan Pembayaran Otomatis Pada Toko Swalayan.Jurnal Penelitian dan Pengembangan Telekomunikasi, Kendali, Kompuer, Elektrik dan Elektonika. Vol. 1, No. 1: 52

Masnur, Alkadri. 2015. Analisa Data Mining Menggunakan Market Basket Analysis untuk Mengetahui Pola Beli Konsumen. Jurnal SATIN. Vol 1, No. 2 Solihin, H.H and Nusa, A.A.F. 2017. Rancang bangun sistem informasi penjualan dan pembelian suku cadang pada bengkel Tiga Putra Motor Garut. Jurnal Inforonik Vol. 2. No. 2: 45

Mulyadi. 2006. Sistem Akuntansi. STIE YKPN, Yogjakarta, Indonesia.

Prawirosentono, Suyadi. 2001. Manajemen Operasi. Edisi Ketiga. Bumi Aksara, Jakarta, Indonesia

Nawy, E. G.(1990). Beton Bertulang Suatu Pendekatan Dasar. Erlangga, Jakarta, Indonesia

Dipohusodo, Istimawan. 1994. Struktur
, Jakarta, Indonesia

Fadlil, A. dkk. 2008.Pengembangan System Basis Data Presensi Perkuliahan dengan Kartu Mahasiswa ber-Barcode. Vol. 6, No. 1, ISSN : 1693-6930.

Rosa. A.S., dan Shalahuddin. M. 2014. Rekayasa Perangkat Lunak. Informatika, Bandung, Indonesia.

Kenneth E. Kendall dan Julie E. Kendall. 2006. Analisis dan Perancangan Sistem. Indeks, Jakarta, Indonesia.

Bagus H.S. 2012. Pemrograman Mikrokontroler dengan Bahasa C. Andi Office. Yogyakarta, Indonesia.

Sultan, U. dan Tirtayasa, A. (2011). Dasar Mikroprosesor. Buku Ajar Universitas Sultan Ageng Tirtayasa, Cilegon, Indonesia. Meka, Y.Q. (2015). Protype Monitoring Area Parkir Mobil Berbasis Arduino Uno Untuk Mendeteksi Ketersediaan Slot Parkir Secara Otomatis Pada Perguruan Tinggi Raharja. Skripsi Sistem Komputer STMIK RAHARJA. Tangerang, Indonesia. 